\title{
Quantitative Image Analysis as a Diagnostic Tool for Monitoring Structural Changes of Anaerobic Granular Sludge During Detergent Shock Loads
}

\author{
J.C. Costa, A.A. Abreu, E.C. Ferreira, M.M. Alves \\ IBB-Institute for Biotechnology and Bioengineering, Center of Biological Engineering, \\ University of Minho, 4710-057 Braga, Portugal; telephone: +351 253 604402; \\ fax: +351253678986; e-mail: madalena.alves@deb.uminho.pt \\ Published online 15 February 2007 in Wiley InterScience (www.interscience.wiley.com). DOI 10.1002/bit.21381
}

ABSTRACT: Two shock loads of a commercial detergent (I-150 mg chemical oxygen demand (COD)/L, fed for $56 \mathrm{~h}$; II-300 mg COD/L fed for $222 \mathrm{~h}$ ) were applied in a lab-scale Expanded Granular Sludge Blanket (EGSB) reactor, fed with $1,500 \mathrm{mg} \mathrm{COD} / \mathrm{L}$ of ethanol. The impact of the surfactant was assessed in terms of granular sludge morphology, specific methanogenic activity (SMA) in the presence of individual substrates, and reactor performance. COD removal efficiency remained unaffected in the shock $\mathrm{I}$, but $80 \mathrm{~h}$ after starting exposure to the shock II, the COD removal efficiency decreased drastically from 75 to $17 \%$. In the first $8 \mathrm{~h}$ of operation of shock I, the SMA was stimulated and decreased afterwards, being recovered 5 days after the end of exposure time. Concerning to shock II, the SMA was immediately and persistently reduced during the exposure time, although, the inhibition of SMA in presence of $\mathrm{H}_{2} /$ $\mathrm{CO}_{2}$ showed a trend to increase after the exposure time. Acetoclastic bacteria were observed as the most sensitive to the toxic effects of surfactant whereas the hydrogenotrophic bacteria were less affected. The inhibitory effects were dependent on surfactant concentration and exposure time. The ratio filaments length per total aggregates area (LfA) was an early-warning indicator of biomass washout, since it increased 3 and 5 days before effluent volatile suspended solids (VSS) rise, respectively, in shocks I and II.

Biotechnol. Bioeng. 2007;98: 60-68.

(C) 2007 Wiley Periodicals, Inc.

KEYWORDS: anaerobic granular sludge; methanogenic activity; image analysis; detergent; surfactant

\section{Introduction}

Industrial wastewaters that are treated by anaerobic digestion processes or have a potential for anaerobic

Correspondence to: M.M. Alves

Contract grant sponsor: Fundação para a Ciência e a Tecnologia

Contract grant number: SFRH/BD/13317/2003 treatment are frequently affected by temporary surfactant loads from cleaning processes (Nagel et al., 1999). In order to optimize the treatment of these wastewaters it is important to know the effects of surfactants on the activity and physical properties of anaerobic aggregates.

Surfactants are water-soluble surface-active agents comprised of a hydrophobic portion, usually a long alkyl chain, attached to hydrophilic functional groups. Detergents, in general, are a class of compounds known to negatively affect the performance of anaerobic digesters (Tanaka and Ichikawa, 1993; Gavala et al., 2001; Feitkenhauer and Meyer, 2002). The active matter of detergents is composed of natural and/or synthetic surfactants of different types (Prats et al., 1997).

Most of the detergents are removed by attachment to the suspended solids (Prats et al., 1997) due to surfactants properties of adsorption (Mosche and Meyer, 2002) and self-assembly. Therefore, surfactant molecules are usually found at the interface between a liquid and a solid phase, influencing its macroscopic properties of wetting, foaming, detergency, and emulsion formation. Self-assembly is the tendency for surfactant molecules to organize themselves into extended structures in water. These structures are formed when the hydrophobic tails of the surfactants cluster together, forming small aggregates such as micelles, or large layer structures (bi-layers), which are similar to a cell wall.

Linear alkylbenzene sulfonate (LAS) are the most common synthetic anionic surfactants used as domestic and industrial detergent (Gavala and Ahring, 2002; Ying, 2006) and are very difficult to be degraded under anaerobic conditions because of their high toxicity to acetoclastic methanogens (Wagner and Schink, 1987; García-Morales et al., 2001). This inference was drawn based on the fact that

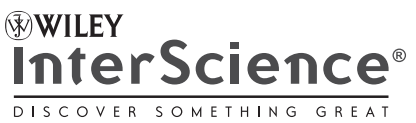


inhibition of methanogenesis was accompanied by the accumulation of acetate (Shcherbakova et al., 1999).

Studies on LAS toxicity indicates that inhibition increases with longer exposure time (Ferrer and Berna, 1999) what suggests that more factors might be influencing the extent of inhibition than just the concentration of surfactants (Mosche and Meyer, 2002).

Granular sludge morphology can be monitored by quantitative image analysis methodologies, which allow understanding mechanisms of erosion, fragmentation, filaments release, and growth. Image analysis was already used to describe the changes on morphology of activated sludge flocs exposed to surfactants (Liwarska-Bizukojc and Bizukojc, 2005), but no reports exist about the effect of such compounds on the structure and morphology of anaerobic granular sludge.

Quantitative image analysis techniques were already applied to the characterization of anaerobic granular sludge and provided objective information about the mechanisms of granulation and granules deterioration processes (Amaral et al., 2004; Araya-Kroff et al., 2004). A parameter relating the free (and protruding) filaments length and the total aggregates projected area was proposed to quantify the morphological structure of the aggregates. This indicator evidenced to be sensitive to alert, with some anticipation, a washout event in an Expanded Granular Sludge Blanket (EGSB) reactor (Amaral et al., 2004).

Integration of morphological analysis of granular sludge, operational, and physiological information is unquestionably a relevant method that allows predicting overall performance and stability of high rate anaerobic reactors in the presence of influent fluctuations, either in terms of flow rate or composition. Surfactants, which are important potential toxicants for anaerobic granular sludge reactors, were never studied in this perspective. The present work aims at presenting and discussing experimental results focused on the effect of detergent shock loads on operational performance and physiological activity of EGSB reactors, combined with morphological information retrieved from quantitative image analysis of anaerobic granular sludge at micro- and macrostructure levels.

\section{Material and Methods}

\section{Experimental Set-Up}

The EGSB reactor was a Plexiglas column (Fig. 1) with a height of $1.95 \mathrm{~m}$ and internal diameter of $21 \mathrm{~mm}$. The working volume was $1.15 \mathrm{~L}$ and the superficial velocity was $3.9 \mathrm{~m} / \mathrm{h}$. Temperature was kept at $37 \pm 1^{\circ} \mathrm{C}$ by means of an external jacket for water circulation.

\section{Detergent Characteristics}

The industrial detergent tested presents a relative density at $20^{\circ} \mathrm{C}$ of 1.04, a $\mathrm{pH}\left(81 \%\right.$ solution at $\left.20^{\circ} \mathrm{C}\right)$ of 11.4 and

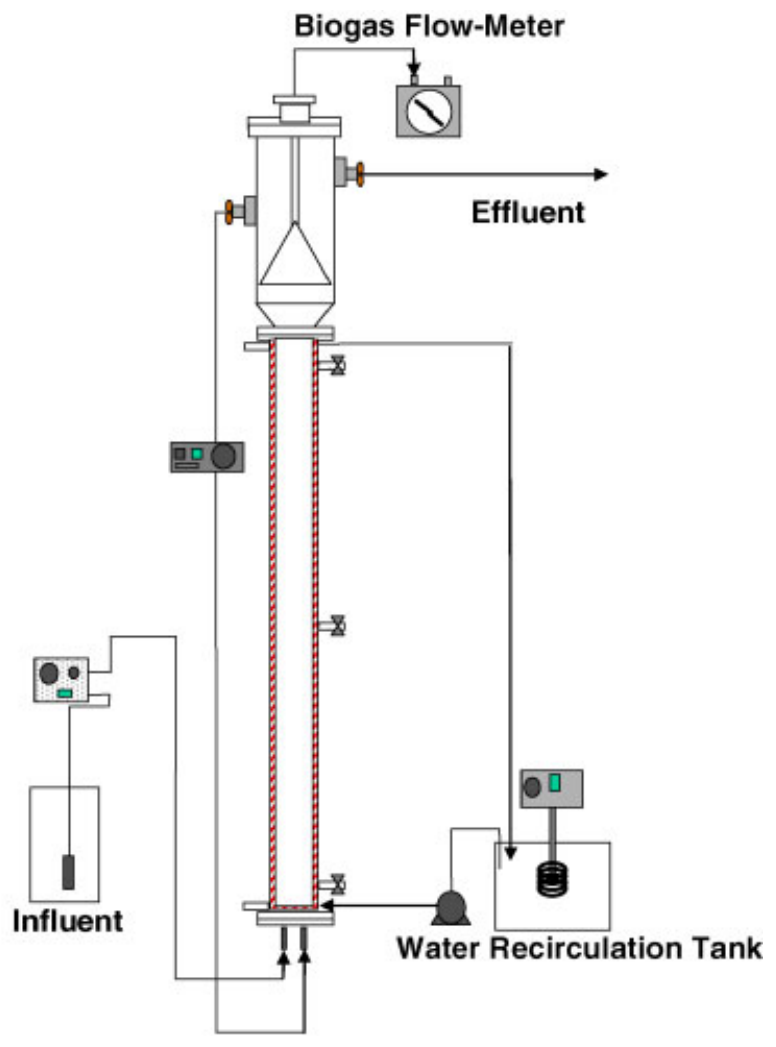

Figure 1. EGSB Reactor. [Color figure can be seen in the online version of this article, available at www.interscience.wiley.com.]

chemical oxygen demand (COD) of $98 \mathrm{~g} / \mathrm{L}$. It is composed by glycol ether (1-10\%), anionic surfactant (1-10\%), performance additives $(1-10 \%)$, dyes $(<1 \%)$, and water $(>60 \%)$.

\section{Inoculum and Substrate}

Four hundred milliliters of granular sludge from a lab-scale EGSB reactor treating a synthetic effluent, with ethanol as sole organic carbon source, was used as the inoculum of the EGSB reactor used in these experiments. The inoculum was characterized in terms of morphology, specific methanogenic activity (SMA) in the presence of acetate and $\mathrm{H}_{2} / \mathrm{CO}_{2}$, settling velocity, and volatile suspended solids (VSS) (Table I).

Ethanol was fed at a concentration of $1.5 \mathrm{~g} \mathrm{COD/L.}$ Sodium bicarbonate was added as the alkalinity source $(3 \mathrm{~g} /$ $\mathrm{L})$ and macro- and micronutrients were added according to Zehnder et al. (1980).

When the reactors were operating in steady-state, two shock loads were then applied (Table I). In the first shock load, a detergent concentration of $150 \mathrm{mg}$ COD/L was used during $56 \mathrm{~h}$ and the recovery was followed through 14 days. In the second shock load the detergent concentration was $300 \mathrm{mg}$ COD/L, the exposure time was $222 \mathrm{~h}$, and the recovery phase was monitored during 12 days. 
Table I. Inocula characterization and detergent shock loads conditions.

\begin{tabular}{|c|c|c|}
\hline & Shock load I & Shock load I \\
\hline \multicolumn{3}{|l|}{ Inoculum characterization: } \\
\hline \multicolumn{3}{|l|}{ Specific methanogenic activity } \\
\hline Acetate (mL CH C@STP $_{4} / \mathrm{g}$ VSS·day) & $150 \pm 22$ & $141 \pm 8$ \\
\hline $\mathrm{H}_{2} / \mathrm{CO}_{2}\left(\mathrm{~mL} \mathrm{CH}_{4 @ S T P} / \mathrm{g}\right.$ VSS·day $)$ & $833 \pm 136$ & $1,028 \pm 103$ \\
\hline \multicolumn{3}{|l|}{ Morphology } \\
\hline LfA $\left(\mathrm{mm}^{-1}\right)$ & 30 & 18 \\
\hline TL/VSS (m/g) & 1,585 & 123 \\
\hline $\mathrm{VSS} / \mathrm{TA}\left(\mathrm{g} / \mathrm{m}^{2}\right)$ & 19 & 27 \\
\hline$D_{\text {eq }}$ macroaggregates $(\mathrm{mm})$ & $0.84 \pm 0.49$ & $0.91 \pm 0.67$ \\
\hline $\operatorname{VSS}(\mathrm{g} / \mathrm{L})$ & 22 & 34 \\
\hline Sedimentation velocity $(\mathrm{m} / \mathrm{h})$ & $29.7 \pm 8.7$ & $30.6 \pm 10.2$ \\
\hline \multicolumn{3}{|l|}{ Shock load conditions: } \\
\hline Ethanol (mg COD/L) & 1,500 & 1,500 \\
\hline Detergent (mg COD/L) & 150 & 300 \\
\hline Exposure time $(\mathrm{h})$ & 56 & 222 \\
\hline Recovery phase (days) & 14 & 12 \\
\hline
\end{tabular}

\section{Routine Analysis}

The COD and VSS were determined according to Standard Methods (APHA et al., 1989). Biogas flow rate was measured by a Ritter Milligascounter (Dr. Ing. Ritter Apparatebau GmbH, Bochum, Germany). Methane content of biogas was determined by gas chromatography using a Porapack $Q$ (100-180 mesh) column, with helium as the carrier gas at 30 $\mathrm{mL} / \mathrm{min}$ and thermal conductivity detector. Temperatures of the detector, injector, and oven were 110,110 , and $35^{\circ} \mathrm{C}$, respectively. Volatile fatty acids (VFA) and ethanol were determined by high performance liquid chromatography using an HPLC (Jasco, Japan) with a Chrompack column $\left(6.5 \times 30 \mathrm{~mm}^{2}\right)$; sulfuric acid $(0.01 \mathrm{~N})$ at a flow rate of 0.7 $\mathrm{mL} / \mathrm{min}$ was used as mobile phase. Column temperature was set at $60^{\circ} \mathrm{C}$. Detection of VFA and ethanol was made sequentially with an UV detector at $210 \mathrm{~nm}$ and a RI detector, respectively.

\section{Specific Methanogenic Activity (SMA) Assays}

The SMA assays were performed using a pressure transducer technique (Colleran et al., 1992; Alves et al., 2001). The specific acetoclastic activity (SAA) was measured in the presence of acetate $(30 \mathrm{mM})$ and the specific hydrogenotrophic methanogenic activity (SHMA) was measured in the presence of $\mathrm{H}_{2} / \mathrm{CO}_{2} 80: 20 \mathrm{~V} / \mathrm{V}$, at 1 bar. No tracenutrients were added. Methane was measured by gas chromatography with helium as the carrier gas and a TCD detector.

\section{Sludge Sampling and Processing for Image Analysis}

The maintenance of granular integrity during sludge sampling and processing was crucial. A sampling device was used to take biomass from the reactor without disturbing its morphology. It consisted of a wide bore tube connected to a $100 \mathrm{~mL}$ syringe. It was introduced at the top of the reactor and biomass was collected to the tube, along the reactor, avoiding mechanical stress. The VSS content was determined for all the samples.

Special care was used for sample dilution. Biomass samples must be diluted for image analysis using an optimized dilution factor. When there are no objects in the image due to an excessive dilution, that image should be registered and considered for calculations. However, the observer may unconsciously search objects, over estimating them. If the dilution is insufficient, the objects will be overlaid. The optimal dilution value was determined as the lowest dilution that enabled the maximum percentage of objects to be recognized. The percentage of recognition is the ratio between the area of objects that are completely inside the image and the total area of objects in the image including those that are at the boundaries and cannot be completely recognized. Depending on sludge concentration and size of aggregates, the optimal dilutions determined for the samples varied between $1 / 5$ and $1 / 10$.

All the sludge samples were characterized by image analysis, SMA assays, settling velocity, and VSS content.

\section{Image Acquisition, Processing, and Analysis}

For the acquisition of filaments and microaggregates $\left(D_{\text {eq }}<0.2 \mathrm{~mm}\right)$ images, a volume of $35 \mu \mathrm{L}$ from the diluted sample was distributed on a slide and covered with a $20 \mathrm{~mm} \times 20 \mathrm{~mm}$ cover slip for visualization and image. This volume was exactly covered by the cover slip. Each image corresponded to a volume of $0.0445 \mu \mathrm{L}$. Then, more than 100 images were acquired. Then, more than 120 images were acquired. Image acquisition was obtained by dividing the cover slip into 42 identical fields and taking a photo in each imaginary square. At least three slides were examined to minimize sampling errors.

Concerning to macroaggregates $\left(D_{\mathrm{eq}} \geq 0.2 \mathrm{~mm}\right)$ images, an arbitrary volume was transferred to a Petri dish for visualization and image acquisition. All the aggregates present in that volume were captured in more than 100 images. Then, the VSS content in the Petri dish was measured.

Images used to quantify filaments and microaggregates were acquired through phase contrast and bright field, respectively, on a Nikon Diaphot 300 microscope (Nikon Corporation, Tokyo) with $100 \times$ magnification. Images used to quantify macroaggregates were acquired through visualization on a Olympus SZ 40 stereo microscope (Olympus, Tokyo) with $15 \times$ magnification. All the images were digitized and saved with the help of a CCD AVC D5CE Sony gray scale video camera (Sony, Tokyo) and a DT 3155 Data Translation frame grabber (Data Translation, Marlboro) with $768 \times 576$ pixel size in 8 bits (256 gray levels) by Image Pro Plus (Media Cybernetics, Silver Spring, MD) software package. 
The metric unit dimensions were further calibrated to pixel using a micrometer slide, for each magnification.

Image processing and analysis was accomplished by means of three programmes developed in Matlab (The Mathworks, Inc., Natick, MA), for filaments, micro- and macroaggregates (Amaral, 2003). In the next paragraphs a brief description of the programs are presented.

The first step of all programs consists in divide the grayscale image by the background image in order to remove background light differences.

\section{Filaments Programme}

A bottom hat filter (Russ, 1995) was applied to enhance the filaments and small aggregates that have low gray levels. The larger aggregates, which have high gray levels, were subsequently identified on the image resulting from the background elimination step by applying a 10-order closing (to enhance the aggregates), a segmentation at a fixed threshold value, a filling of the resulting binary image (to remove the inner holes in the aggregates) and a erosionreconstruction step to eliminate the debris. Filaments and small aggregates were then isolated by segmentation at a fixed threshold and by logic subtraction of the mask binary image containing the large aggregates. Then, the small aggregates were eliminated by deleting all the objects smaller than 32 pixels (in area) or with a gyration radius below 1.2 (Pons and Vivier, 1999). The final image contained only filaments that were characterized in terms of their length and number. The filaments image was skeletonised and pruned (Russ, 1995). The filaments length was determined by:

$$
L=N \times 1.122 \times F_{\text {cal }}
$$

where $N$ is the number of pixels of the skeletonised filament and $F_{\text {cal }}$ is the calibration factor $(\mu \mathrm{m} / \mathrm{pixel})$. The factor 1.1222 is used in order to homogenize the different angles of the filaments (Walsby and Avery, 1996). Finally, the specific total filament length was calculated as $L_{\text {spec }}=L / V_{\text {field }}$ where $V_{\text {field }}$ is the volume (in $\mu \mathrm{m}^{3}$ ) corresponding to the field of view (i.e., the image).

Filaments are not only the dispersed bulk filaments, but include also those that are attached to an aggregate and still have one free extremity (protruding filaments).

\section{Micro- and Macroaggregates Programs}

Firstly, histogram equalization was performed to enhance the microaggregates (this step only occurs in the microaggregates program). Afterwards, the image was smoothed by a Wiener filtering (Glasbey and Horgan, 1995). Then, it segmented in black (background) and white (aggregates) by the simultaneous use of a boundary based segmentation and a user chosen or automatically determined threshold segmentation. The objects smaller than $3 \times 3$ pixels (small debris) were then removed and small gaps $(6 \times 6$ pixels or less) were filled on the remaining objects. Subsequently, in order to remove filaments, all the objects smaller than 2,000 pixels in area and with a gyration radius above 1.2 (Pons and Vivier, 1999) were deleted (microaggregates program). Finally, all the objects cut off by the image boundaries were removed, and the morphological characterization of the micro- and macroaggregates were performed.

The parameters determined by these two programs are the aggregate area from which the equivalent diameter $\left(D_{\mathrm{eq}}\right)$ is calculated:

$$
D_{\text {eq }}=2 F_{\text {cal }} \sqrt{\frac{\text { Area }}{\pi}}
$$

and the total area $\left(A_{\mathrm{T}}\right)$ occupied by aggregates in each image from which the specific area occupied by aggregates is calculated:

$$
A_{\text {spec }}=\frac{A_{\mathrm{T}}}{V_{\text {field }}}
$$

Finally, a morphological parameter based on the ratio of specific total filament length $\left(L_{\text {spec }}\right)$ to total aggregates projected area (LfA) is determined:

$$
\mathrm{LfA}=\frac{L_{\mathrm{spec}}}{A_{\mathrm{spec}(<0.2 \mathrm{~mm})}+A_{\mathrm{spec}(\geq 0.2 \mathrm{~mm})}}
$$

where $A_{\text {spec }(<0.2 \mathrm{~mm})}$ and $A_{\mathrm{spec}(\geq 0.2 \mathrm{~mm})}$ are the specific aggregate area ratio for aggregates of equivalent diameter $<0.2$ and $\geq 0.2 \mathrm{~mm}$, respectively.

\section{Settling Velocity}

The sedimentation velocity was measured by depositing several biomass samples in the top of a column filled with water. Afterwards the time that each particle takes to cover the $320 \mathrm{~mm}$ of the column was measured using a chronometer that automatically registers that time in an Excel spreadsheet. Then it was determined the average of all individual sedimentation velocities of the particles settled. More than 150 particles were observed.

\section{Results and Discussion}

\section{Shock Load With $150 \mathrm{mg}$ COD/L of Detergent}

\section{Operational Parameters}

The reactor was operated at a hydraulic retention time (HRT) of $7.8 \mathrm{~h}$, and it was fed with 1,650 mg COD/L during the exposure time. When the detergent was removed from the feeding (after $56 \mathrm{~h}$ ), the $\mathrm{COD}_{\text {in }}$ was $1,380 \mathrm{mg} \mathrm{COD} / \mathrm{L}$, corresponding to a reduction on the organic loading rate (OLR) from 5.0 to $4.3 \mathrm{~kg} \mathrm{COD} / \mathrm{m}^{3}$. day (Fig. 2).

No significant effects were observed in the reactor performance caused by the shock load. The COD detected 


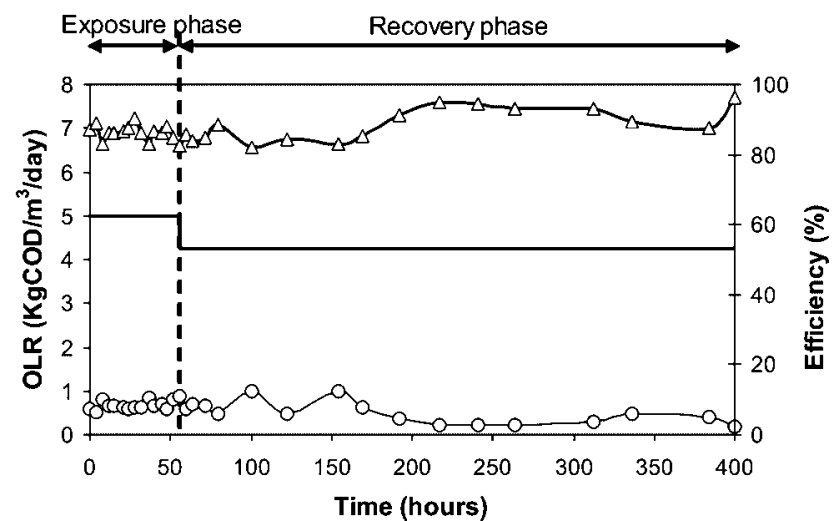

Figure 2. Time course of operational parameters in shock load I. (-) Influent organic loading rate. $(\triangle) \operatorname{COD}$ removal efficiency, $(O)$ effluent organic loading rate.

in the effluent was roughly constant during the exposure and recovery phase, corresponding to an OLR lower than $1 \mathrm{~kg}$ $\mathrm{COD} / \mathrm{m}^{3}$ effluent.day. Consequently the COD removal efficiency was consistently above $80 \%$ throughout the operational period. The $\mathrm{pH}$ changed from $8.0 \pm 0.1$ during the exposure time to $7.8 \pm 0.2$ in the recovery phase. This fact suggests that the detergent concentration did not affect significantly the $\mathrm{pH}$ inside the reactor.

\section{Methanogenic Activity}

Figure 3, shows the SMA results in the presence of acetate and $\mathrm{H}_{2} / \mathrm{CO}_{2}$ as substrates, measured through the exposure and recovery phases.

At the beginning of shock load (first $8 \mathrm{~h}$ ) the SMA was stimulated by the detergent. It was already reported by Mosche and Meyer (2002) that at low concentrations $(<3 \mathrm{mg} / \mathrm{L})$, surfactants can induce stimulation on bacterial activity. However, after the initial stimulation, the SHMA

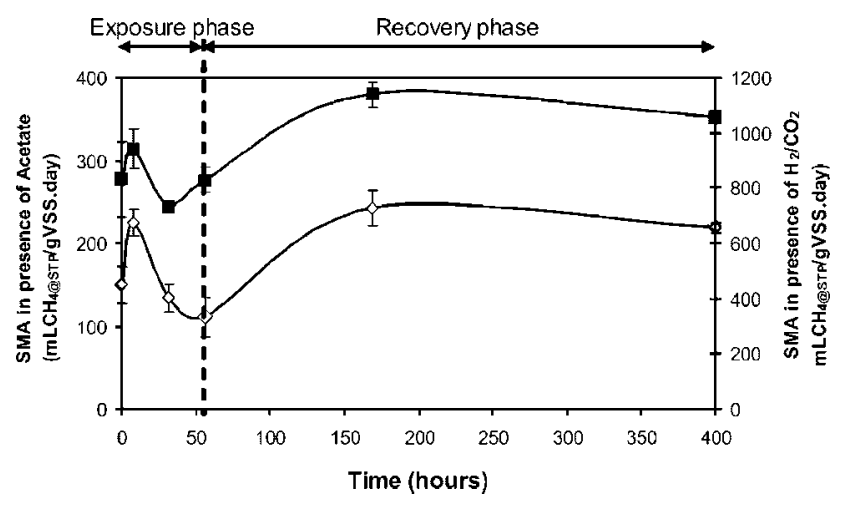

Figure 3. Time course of the specific methanogenic activity (SMA) in presence of acetate $(\diamond)$, and $\mathrm{H}_{2} / \mathrm{CO}_{2}(\boldsymbol{\square})$ as substrates, in shock load I. was inhibited during the next $24 \mathrm{~h}$ of exposure and started to recover afterwards. The decrease in the SAA was more pronounced than in the SHMA, once it decreased until the end of the exposure period. The results suggest that the SAA might be the most sensitive to the toxic effects of the detergent. Other authors already reported that acetoclastic methanogens were more affected by surfactant toxicity (García-Morales et al., 2001; Mosche and Meyer, 2002).

During the recovery phase the SMA achieved higher values than the ones presented by the inoculum. This suggests that the effects of detergent shock load with $150 \mathrm{mg}$ $\mathrm{COD} / \mathrm{L}$ of detergent were reversible approximately $113 \mathrm{~h}$ after the end of exposure time and therefore was not permanent..

\section{Image Analysis}

The use of image analysis techniques allowed the quantification of several changes in morphological parameters of biomass, such as, the ratio between total filaments length (free and protruding filaments) and total aggregates projected area (LfA). This parameter represents the dynamics involving filaments and aggregates inside the reactor. The total filaments length per VSS (TL/VSS) and the percentage of total projected area of aggregates distribution in each equivalent diameter classes characterizes the filament and the aggregate dynamics individually. The ratio between VSS and total projected area of aggregates (VSS/TA) reflects the apparent granules density.

During the first $8 \mathrm{~h}$ of exposure, the toxic effects of detergent on anaerobic granular sludge was showed by an increase of filamentous forms released from the aggregates, represented by an increase of TL/VSS (Fig. 4b) that induced an increase of LfA value in the bulk (Fig. 4a). In this first stage, the granules become less dense as evidenced by the VSS/TA decrease (Fig. 4b). This might be explained by the surfactants adsorption and self-assembly properties. This fact was also verified by the decrease of granules average sedimentation velocities $\left(v_{\text {sed }}\right)$ from $29.7 \pm 8.7$ to $25.1 \pm 10.8 \mathrm{~m} / \mathrm{h}$.

After this adaptation phase, and regardless of the intrinsic evolution of both parameters involved in the LfA definition, it was observed a significant increase of LfA until the end of exposure time $(56 \mathrm{~h})$, which was a result of the important release of filaments detected by the increase of TL/VSS. The percentage of projected area of aggregates larger than $1 \mathrm{~mm}$ was consistently above $80 \%$ throughout this period (Fig. 4c) although an increase of the percentage of aggregates small than $0.1 \mathrm{~mm}$ was detected, possibly due to adsorption or self-assembly of surfactants onto the granules.

The last stage corresponds to the recovery phase. Here, LfA starts to decrease, suggesting a change in the dynamics of filaments and aggregates. This may be explained by the washout of the free filaments and consequent decrease of TL/VSS from 6,150 to $870 \mathrm{~m} / \mathrm{g}$ VSS (Fig. 4b), and the enhancement in consistency of the granules as a consequence of the increase of VSS/TA from 10 to $20 \mathrm{~g}$ VSS $/ \mathrm{m}^{2}$. 


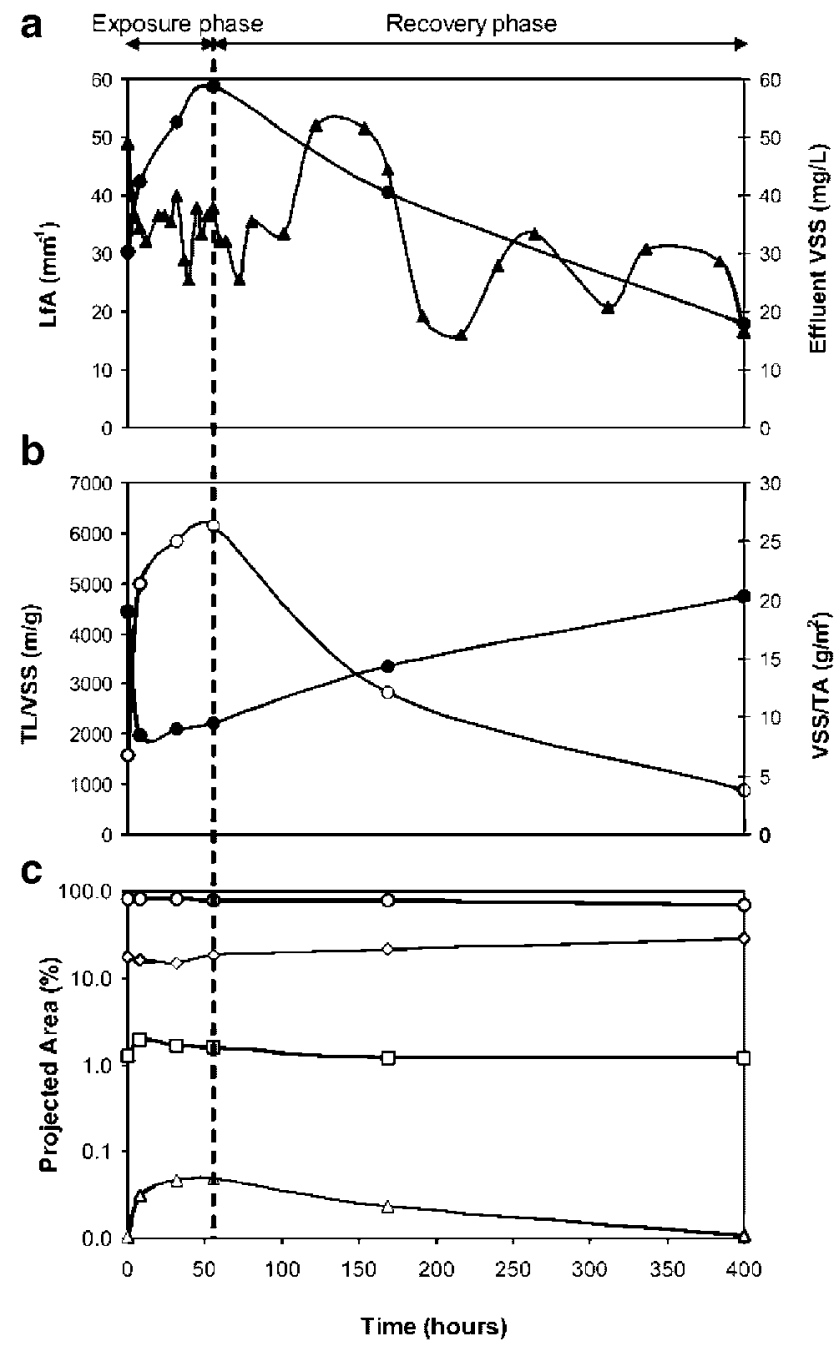

Figure 4. Time course of morphological parameters in shock load I: (a) dynamic between total filament length and total aggregates projected area (LfA, O) and effluent volatile suspended solids (effluent VSS, $\mathbf{\Delta}$ ), (b) total filament length per volatile suspended solids (TL/VSS, $O$ ) and volatile suspended solids per total aggregates projected area (VSS/TA, O), and (c) percentage of projected area for different size classes of aggregates equivalent diameter. $(\bigcirc) D_{\text {eq }} \geq 1 \mathrm{~mm} ;(\diamond) 0.1$ $\mathrm{mm} \leq D_{\text {eq }}<1 \mathrm{~mm} ;(\square) 0.01 \mathrm{~mm} \leq D_{\text {eq }}<0.1 \mathrm{~mm} ;(\triangle) D_{\text {eq }}<0.01 \mathrm{~mm}$.

The $v_{\text {sed }}$ slightly increased from $25.1 \pm 10.8$ to $28.2 \pm 14.7 \mathrm{~m} /$ h. During this phase the effluent $\mathrm{VSS}_{\text {out }}$ started to increase (Fig. 4a). LfA raised between 0 and $56 \mathrm{~h}$ and $\mathrm{VSS}_{\text {out }}$ only increase after $101 \mathrm{~h}$ of operation, suggesting that LfA might be an earlier warning indicator of washout in detergent shock loads. Amaral et al. (2004) provides an explanation to the possible earlier detection of washout based on the mechanism of filaments release, detachment, selective washout, and LfA calculation method.

According to these authors, when the granules begin to fragment, the filaments start to be released from the granules into the bulk, consequently, the LfA increases due to detection of free filaments and filaments still attached to the granules (protruding filaments). Only in a subsequent phase, when the washout of the free filaments and small aggregates occurs, the $\mathrm{VSS}_{\text {out }}$ increases. In this phase the LfA decreases, since inside the reactor only the bigger aggregates and the residual protruding filaments remain.

\section{Shock Load With $300 \mathrm{mg}$ COD/L of Detergent}

A second shock was applied with a higher concentration of detergent $(300 \mathrm{mg}$ COD/L). The exposure time was extended to $222 \mathrm{~h}$. The objective was to study the influence of concentration and exposure time in the anaerobic biodegradation of organic compounds in the presence of detergent/surfactant.

During the operation period, three stages were distinguished, the operation period I (OPI) occurred until the 80th h, operation period II (OPII) from the 80th h until the end of exposure phase $(222 \mathrm{~h})$, and the operation period III (OPIII) corresponds to the recovery phase, from 222 to $505 \mathrm{~h}$

\section{Operation Period I}

The reactor was fed with $1,960 \mathrm{mg} C O D / \mathrm{L}$ corresponding to an OLR of $6.3 \mathrm{Kg} \mathrm{COD} / \mathrm{m}^{3}$.day (Fig. 5-OPI). The HRT was $7.5 \mathrm{~h}$.

In the first $80 \mathrm{~h}$, the COD removal efficiency was constantly above $75 \%$, and the effluent COD was roughly constant, around $400 \mathrm{mg} \mathrm{COD} / \mathrm{L}$, corresponding to an OLR of $1.3 \mathrm{Kg} \mathrm{COD} / \mathrm{m}^{3}$ effluent.day (Fig. 5-OPI).

It has been reported that the removal of surfactants from the liquid phase is partially due to adsorption at the biomass (Mosche and Meyer, 2002). Mensah and Forster (2003) suggested that the detergent removal from the wastewater is achieved through a combination of adsorption and degradation. So, if we assume that surfactants primarily adsorb to cell membranes (Helenicus and Simons, 1975), severe damage of the membrane functions and cell viability

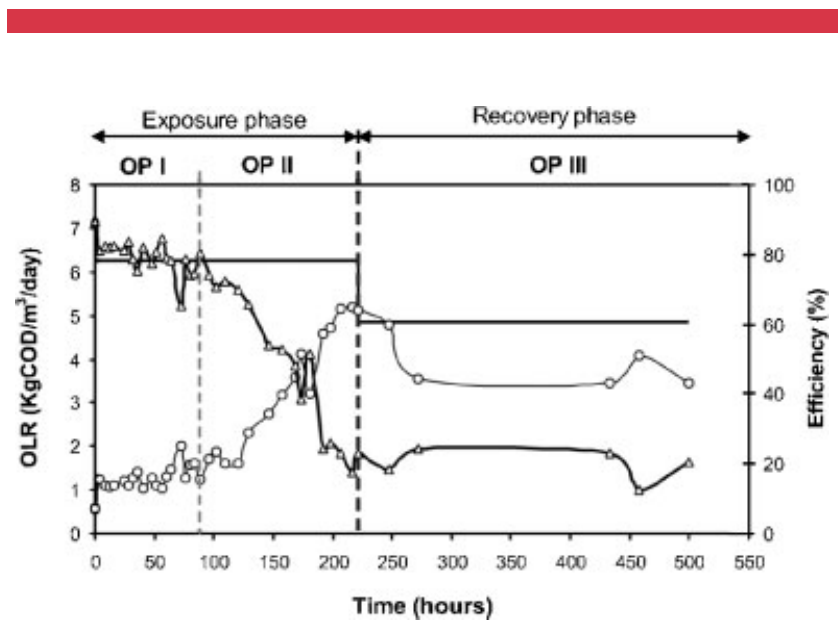

Figure 5. Time course of operational parameters in shock load II. (-) Influent organic loading rate. $(\Delta)$ COD removal efficiency, $(O)$ effluent organic loading rate. 
can be expected, especially in the transport of nutrients and/ or substrate into bacterial cells (Gavala and Ahring, 2002).

A detergent concentration of $300 \mathrm{mg} C O D / L$ immediately started to have an inhibitory effect in the SAA. However, the SHMA was improved in the first $32 \mathrm{~h}$ of exposure, suggesting that the hidrogenotrophic bacteria were the less affected by the detergent. During this operation stage the SAA was lost, achieving negligible values in the 80th $\mathrm{h}$ of exposure (Fig. 6-OPI). These results indicate that the acetoclastic bacteria were the most affected by the toxic effect of the detergent.

In the beginning of experiment the TL/VSS showed a slightly increase caused by filaments release to the bulk. In the next hours of operation TL/VSS decreased possibly because of washout of free filaments (Fig. $7 \mathrm{~b}-\mathrm{OPI}$ ). The granules consistency decreased due to adsorption and selfassembly of the surfactants. In fact, the VSS/TA presented a decreasing trend during this period (Fig. $7 \mathrm{~b}-\mathrm{OPI}$ ). Simultaneously, the $v_{\text {sed }}$ decreased from $30.6 \pm 10.2$ to $24.0 \pm 13.5 \mathrm{~m} / \mathrm{h}$, proving that the aggregates became fluffier. As expected, in this phase, the LfA parameter presented the same behavior as the shock load I, it increased from 18 to $43 \mathrm{~mm}^{-1}$ in the first $24 \mathrm{~h}$ of operation. After this adapting phase it decreased to $20 \mathrm{~mm}^{-1}$. Simultaneously a small decrease of $\mathrm{VSS}_{\text {out }}$ from 60 to $27 \mathrm{mg} / \mathrm{L}$ was observed (Fig. $7 \mathrm{a}-\mathrm{OPI}$ ).

\section{Operation Period II}

After the first $80 \mathrm{~h}$ of operation, the COD removal efficiency dropped consistently, reaching the value of $17 \%$ at the end of exposure time (Fig. 5-OPII). Simultaneously, the methane production was continuously reduced, presenting negligible values at the end of this stage (data not showed), and the effluent COD increased constantly (Fig. 5-OPII). It is relevant to note that the loss of performance was acute only after the complete inhibition of the SAA (Fig. 6OPII). Relatively to SHMA a decrease between 80 and $222 \mathrm{~h}$

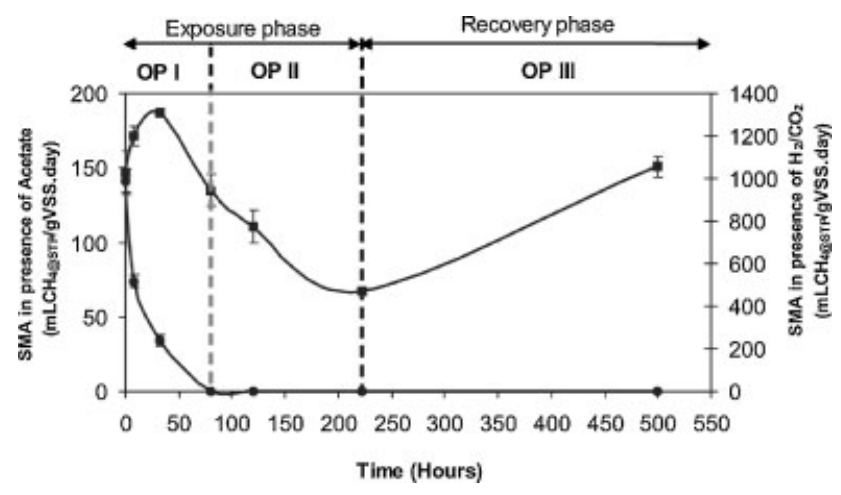

Figure 6. Time course of the specific methanogenic activity (SMA) in presence of acetate $(\diamond)$, and $\mathrm{H}_{2} / \mathrm{CO}_{2}(\boldsymbol{\square})$ as substrates, in shock load II.

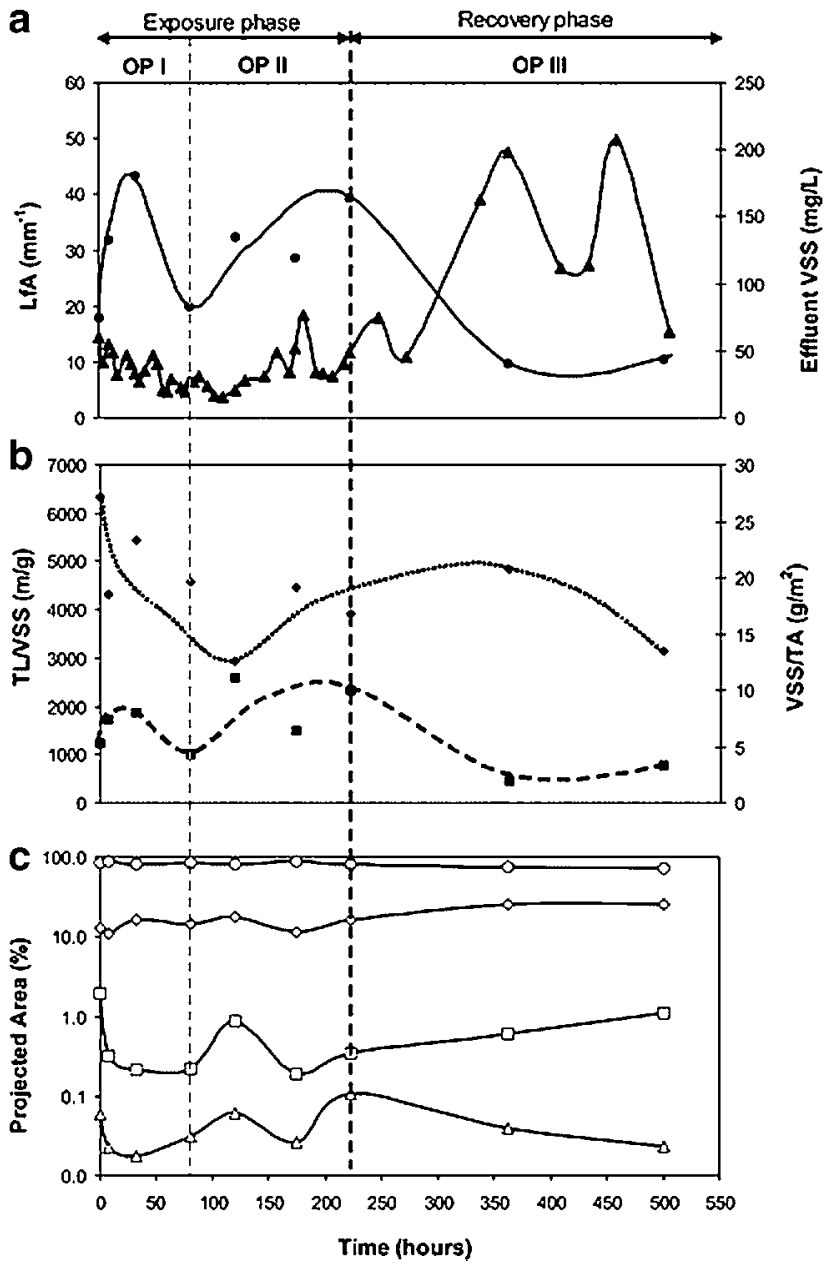

Figure 7. Time course of morphological parameters in shock load II: (a) dynamic between total filament length and total aggregates projected area (LfA, $\bullet$ ) and effluent volatile suspended solids (effluent VSS, $\mathbf{\Delta}$ ), (b) total filament length per volatile suspended solids (TL/VSS, O) and volatile suspended solids per total aggregates projected area (VSS/TA, $\bullet$ ), and, (c) percentage of projected area for different size classes of aggregates equivalent diameter. $(O) D_{\mathrm{eq}} \geq 1 \mathrm{~mm} ;(\diamond) 0.1$ $\mathrm{mm} \leq D_{\text {eq }}<1 \mathrm{~mm}$; $(\square) 0.01 \mathrm{~mm} \leq D_{\text {eq }}<0.1 \mathrm{~mm} ;(\Delta) D_{\text {eq }}<0.01 \mathrm{~mm}$.

was observed, inducing the idea that the negative effects of surfactant increased during the exposure time, even to the less sensitive bacteria.

Concerning the image analysis results, it was observed that the effects of detergent shock load on the morphological parameters caused an increase on LfA to $39 \mathrm{~mm}^{-1}$ (Fig. 7a-OPII). This result was a response to the behavior of filament dynamics inside the reactor. The filaments started to be released from the granules into the bulk, and TL/VSS increase (Fig. 7b-OPII), inducing the increase of LfA parameter. In this phase, the protruding filaments were in higher length and the increase of VSS out $_{\text {was minimal, }}$ since only the free filaments and fluffier granules were washed out. Consequently, it was observed that the VSS/TA parameter presented an increasing trend (Fig. $7 \mathrm{~b}-\mathrm{OPII}$ ) because only the denser granules remained inside the reactor. 
When the filaments were released the percentages of the smaller aggregates $\left(D_{\text {eq }}<0.1 \mathrm{~mm}\right)$ increased, and, after an occurrence of washout (increase of VSS), these percentages returned close to the initial values (Fig. $7 \mathrm{c}$-OPII).

\section{Operation Period III}

In this phase the $\mathrm{COD}_{\text {in }}$ was reduced to $1,530 \mathrm{mg} C O D / \mathrm{L}$, corresponding to an OLR of $5 \mathrm{Kg} \mathrm{COD} / \mathrm{m}^{3}$.day. During the recovery phase, no improvement in the reactor performance was observed. The COD removal efficiency was persistently lower than $25 \%$ (Fig. 5-OPIII). These results suggest that the inhibitory effects caused by $300 \mathrm{mg} C O D / L$ of detergent, were irreversible during $283 \mathrm{~h}$ after the end of exposure time.

Relatively to the SAA (Fig. 6-OPIII), no recovery was detected during 12 days after exposure. Gavala and Ahring (2002) showed that methanogenesis from hydrogen was affected by the surfactants in much lower range. In this experiment it was observed that, although the SHMA was reduced during the exposure time, in the recovery phase it completely recovered. This result confirms that hydrogenotrophic bacteria are less affected by the surfactant.

In this phase the VSS out increased to values near $200 \mathrm{mg} / \mathrm{L}$ (Fig. 7a-OPIII). This fact may be explained by the washout of the small aggregates, observed by a decrease of the percentage of projected area of aggregates smaller than $0.01 \mathrm{~mm}$ (Fig. 7b-OPIII). Other possible reason of $\mathrm{VSS}_{\text {out }}$ increase was the washout of free filaments, and consequent decrease of TL/VSS (Fig. 7b-OPIII). These facts induced the reduction of LfA parameter to the lowest value $\left(10 \mathrm{~mm}^{-1}\right)$ (Fig. $7 \mathrm{a}-$ OPIII).

In detergent shock I discussion it was hypothesized that LfA could be an early-warning indicator of biomass washout. The results of this shock load (LfA raise between 80 and $222 \mathrm{~h}$ and VSS $_{\text {out }}$ increase, only, after $272 \mathrm{~h}$ ), emphasize this hypothesis.

\section{Conclusions}

Phenomena of granular erosion, growth, and filaments release were identified and quantified, for the first time, during the operational response of an EGSB reactor to detergent shock loads.

The COD removal efficiency was unaffected with $150 \mathrm{mg}$ COD/L (56 h exposure time) of detergent. The SMA was stimulated in the first $8 \mathrm{~h}$ of exposure with $150 \mathrm{mg} C O D / \mathrm{L}$ of detergent. After this increase, an inhibitory effect was detected. Nevertheless, the SMA was recovered 5 days after the end of exposure time. However, $80 \mathrm{~h}$ after exposure to $300 \mathrm{mg}$ COD/L of detergent, the COD removal efficiency decreased from 75 to $17 \%$. In this experiment, significant changes in the SMA and granular sludge morphology were detected immediately after exposure to surfactant $(300 \mathrm{mg} / \mathrm{L})$, whereas operational performance only deteriorated after $80 \mathrm{~h}$ of exposure time. It is relevant to note that in these conditions, the loss of performance was acute only after the complete inhibition of the SAA. The acetoclastic bacteria were the most sensitive to the inhibitory effect of surfactant and the hydrogenotrophic bacteria the least sensitive. The inhibitory effects were dependent on surfactant concentration and exposure time.

Image analysis techniques allowed quantifying the structural stability of anaerobic granular sludge. Both detergent shocks induced an immediate increase of free filaments in the bulk medium, from 1,600 to $6,150 \mathrm{~m} / \mathrm{g}$ VSS and from 1,200 to $1,850 \mathrm{~m} / \mathrm{g}$ VSS, in the $150 \mathrm{mg} / \mathrm{L}$ and in the $300 \mathrm{mg} / \mathrm{L}$ detergent shock, respectively. No significant size reduction was observed in the larger aggregates in both shocks.

The filaments length/total aggregate area (LfA) parameter confirmed to be sensitive to detect changes in the sludge morphology. LfA increased 3 and 5 days before the detection of a severe washout event, in shock loads I and II, respectively, suggesting that in the present experiment it could have been an early-warning indicator of biomass washout.

We grateful acknowledge the financial support to José Carlos Costa and Ângela Abreu through the grant SFRH/BD/13317/2003 and the project POCTI/BIO/37934/2001, respectively, from the Fundação para a Ciência e a Tecnologia (Portugal).

\section{References}

Alves MM, Mota Vieira JA, Álvares Pereira RM, Pereira MA, Mota M. 2001. Effects of Lipids and Oleic Acid on Biomass Development in Anaerobic Fixed Bed Reactors. Part I: Biofilm growth and activity. Water Res 35:255-263.

Amaral AL. 2003. Image Analysis in Biotechnological Processes: Application to Wastewater Treatment. PhD dissertation, University of Minho, Portugal. (http://hdl.handle.net/1822/4506).

Amaral AL, Pereira MA, da Motta M, Pons M-N, Mota M, Ferreira EC, Alves MM. 2004. Development of image analysis techniques as a tool to detect and quantify morphological changes in anaerobic sludge: II. Application to a granule deterioration process triggered by contact with oleic acid. Biotechnol Bioeng 87(2):194-199.

APHA, AWWA, WPCF. 1989. Standard methods for the examination of water and wastewater, 17th ed. Washington, DC: American Public Health Association.

Araya-Kroff P, Amaral AL, Neves L, Ferreira EC, Pons M-N, Mota M, Alves MM. 2004. Development of image analysis techniques as a tool to detect and quantify morphological changes in anaerobic sludge: I. Application to granulation process. Biotechnol Bioeng 87(2):184-193.

Colleran E, Concannon F, Goldem T, Geoghegan F, Crumlish B, Killilea E, Henry M, Coates J. 1992. Use of methanogenic activity tests to characterize anaerobic sludges, screen for anaerobic biodegradability and determine toxicity thresholds against individual anaerobic tropic groups and species. Water Sci Technol 25:31-40.

Feitkenhauer H, Meyer U. 2002. Anaerobic digestion of alcohol sulphate (anionic surfactant) rich wastewater - batch experiments. Part I: Influence of the surfactant concentration. Bioresour Technol 82:115-121.

Ferrer J, Berna JL. 1999. Evaluation of the toxicity of Na LAS (linear alkylbenzene sulfonte) to anaerobic methanogenic process. Chim Oggi 17:22-24.

García-Morales JL, Nebot E, Romero LI, Sales D. 2001. Comparison between acidogenic and methanogenic inhibition caused by linear alkylbenzene sulfonate (LAS). Chem Biochem Eng Q 15:13-19. 
Gavala HN, Haagensen F, Mogensen AS, Angelidaki I, Ahring BK. 2001. Linear alkylbenzene sulfonates: inhibition effects on acetate and propionate degradation during anaerobic digestion. Proceedings 4th International Symposium Environmental Biotechnology. p 452-455.

Gavala HN, Ahring BK. 2002. Inhibition of the anaerobic digestion process by linear alkylbenzene sulfonates. Biodegradation 13:201-209.

Glasbey CA, Horgan GW. 1995. Image analysis for the biological sciences. Chichester: John Wiley and Sons.

Helenicus A, Simons K. 1975. Solubilization of membranes by detergents. Biochim Biophys Acta 415:29-79.

Liwarska-Bizukojc E, Bizukojc M. 2005. Digital image analysis to estimate the influence of sodium dodecyl sulphate on activated sludge flocs. Proc Biochem 40:2067-2072.

Mensah KA, Forster CF. 2003. An examination of the effects of detergents on anaerobic digestion. Biores Technol 90:133-138.

Mosche M, Meyer U. 2002. Toxicity of linear alkylbenzenesulfonate surfactants in sewage sludge. Naturwissenschaften 72:429-431.

Nagel P, Urtubia A, Aroca G, Chamy R, Schiappacasse M. 1999. Methanogenic toxicity and anaerobic biodegradation of chemical products in use in a brewery. Water Sci Technol 40(8):169-176.

Pons MN, Vivier H. 1999. Biomass quantification by image analysis. Adv Biochem Eng/Biotechnol 66:133-184.
Prats D, Ruiz F, Vásquez B, Rodriguez-Pastor M. 1997. Removal of anionic and nonionic surfactants in wastewater treatment plant with anaerobic digestion. A comparative study. Water Res 31(8):1925-1930.

Russ CR. 1995. The image processing handbook. Boca Raton, FL: CRC Press.

Shcherbakova VA, Laurinavichius KS, Akimenko VK. 1999. Toxic effect of surfactants and probable products of their biodegradation on methanogenesis in an anaerobic microbial community. Chemosphere 39(11): 1861-1870.

Tanaka S, Ichikawa T. 1993. Effects of photolytic pre-treatment on biodegradation and detoxification of surfactants in anaerobic digestion. Water Sci Technol 28(7):103-110.

Wagner S, Schink B. 1987. Anaerobic degradation of non-ionic and anionic surfactants in enrichment cultures and fixed-bed reactors. Water Res 21:615-622.

Walsby AE, Avery A. 1996. Measurement of filamentous cyanobacteria by image analysis. J Microbiol Methods 26:11-20.

Ying G-G. 2006. Fate, behavior and effects of surfactants and their degradation products in the environment. Environ Int 32:417-431.

Zehnder AJB, Huser BA, Brock TD, Wuhrmann K. 1980. Characterization of an acetate-decarboxylating, non-hydrogen-oxidizing methane bacterium. Arch Microbiol 124:1-11. 